\title{
Erratum to: In vivo Tn5-based transposon mutagenesis of Streptomycetes
}

\author{
Lutz Petzke • Andriy Luzhetskyy
}

Published online: 30 March 2010

(C) Springer-Verlag 2010

\section{Erratum to: Appl Microbiol Biotechnol}

\section{DOI 10.1007/s00253-009-2047-z}

The article unfortunately contained a mistake.

The GenBank accession number mentioned in the text (FJ15958, page 980, subchapter Plasmid construction) is wrong, it should be FJ715958.

The online version of the original article can be found at http://dx.doi. org/10.1007/s00253-009-2047-z.

L. Petzke · A. Luzhetskyy $(\bowtie)$

Department of Pharmaceutical Biology and Biotechnology,

Albert-Ludwigs-University of Freiburg,

Stefan-Meier st. 19,

Freiburg, 79104, Germany

e-mail: andriy.luzhetskyy@pharmazie.uni-freiburg.de 